ambulation since the patients have less postoperative pain.

The article by Nakamura et al. asks what to do when patients do not comply with the IPCD. My suggestion would be to emphasize to the nurses and the patient the importance of the devise and in addition use a spinal anesthetic. Our patients remove the devices the morning after surgery and begin ambulation.

\section{References}

1. Geerts WH, Pineo GF, Heit JA, Bergqvist D, Lassen MR, Colwell CW, et al: Prevention of venous thromboembolism: the seventh ACCP conference on antithrombotic and thrombolytic therapy. Chest. 2004; 126: 338S-400S.

2. Sved P, Nieder A, Manoharan M, Gomez P, Meinbach DS, Kim SS, et al: Evaluation of analgesic requirements and postoperative recovery after radical retropubic prostatectomy utilizing long acting spinal anesthesia. Urology. 2005; 65: 509-12.

3. Koya MP, Manoharan M, Kim S, Soloway MS: Venous thromboembolism in radical prostatectomy: is heparanoid prophylaxis warranted? BJU Int. 2005; 96: 1019-21.

4. Rodgers A, Walker N, Schug S, McKee A, Kehlet H, van Zundert A, et al: Reduction of postoperative mortality and morbidity with epidural or spinal anesthesia: results from overview of randomised trials. BMJ. 2000; 321: 1493.

Dr. Mark S. Soloway

Professor \& Chair, Department of Urology Miller School of Medicine, University of Miami

Miami, Florida, USA

E-mail: MSoloway@med.miami.edu

\title{
Re: Inflammatory Atrophy on Prostate Needle Biopsies: Is There Topographic Relationship to Cancer?
}

\author{
Athanase Billis, Leandro L.L.Freitas, Luis A. Magna, Ubirajara Ferreira \\ Departments of Anatomic Pathology (AB,LLLF), Genetics and Biostatistics (LAM), and Urology(UF), \\ School of Medicine, State University of Campinas (Unicamp), Campinas, São Paulo, Brazil
}

Int Braz J Urol 2007;33:355-63

To the Editor:

The editorial comments of our paper by Dr.H.Samaratunga, Dr. Rodolfo Montironi, and Dr. Liang Cheng were very informative on a lesion that is one of the most frequent mimics of prostatic adenocarcinoma. It occurs most frequently in the posterior lobe or peripheral zone (1-3) and gained im- portance with the increasing use of needle biopsies for the detection of prostatic carcinoma (4). Moore (1), in 1936, was one of the first authors to describe prostatic atrophy in a systematic autopsy study. He found that there was a strong correlation with age and, according to his study, prostatic atrophy is initi- 
ated during the 5th decade and continues as a progressive process into the 8 th decade. It is a frequent lesion: $85 \%$ in autopsies and $83.7 \%$ in needle biopsies $(5,6)$.

Why this lesion mimics adenocarcinoma? Histologically prostatic atrophy may be partial or complete. The latter is subtyped in simple, hyperplastic (or post-atrophic hyperplasia), and sclerotic (5). It seems that the subtypes represent a morphologic continuum of a single lesion (4). Partial atrophy and hyperplastic (or postatrophic hyperplasia) most frequently mimic adenocarcinoma. Hyperplastic atrophy shows small acini closely packed together and lined by atrophic epithelium. Fibrosis is present or not in the stroma. When present, the proliferation is irregular and can result in distortion of the acini simulating stromal infiltration (Figure-1). Partial atrophy was described by Oppenheimer et al. (7). The name is due to the fact that there is partial preservation of the cytoplasm simulating neoplastic micro-acini (Figure-2). An additional pitfall for the surgical pathologist is the fact that in partial atrophy the basal cells may be scattered and in some acini may be completely absent (Figure-3).

There are some findings associated to the etiopathogenesis of the lesion. Atrophy is clearly associated to advanced age $(1,5)$. Radiotherapy and hormonal deprivation are associated with diffuse atro-

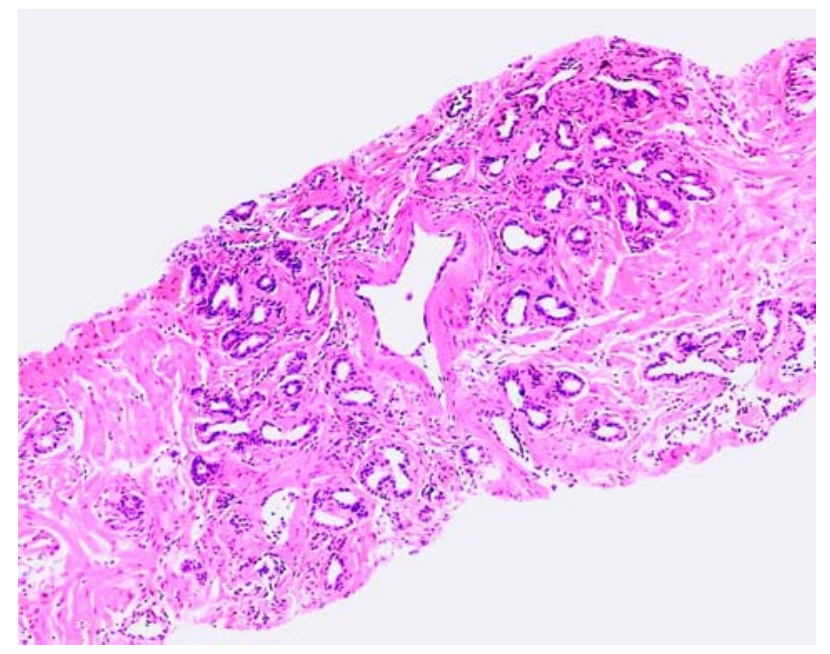

Figure 1 - Hyperplastic atrophy (or postatrophic hyperplasia).

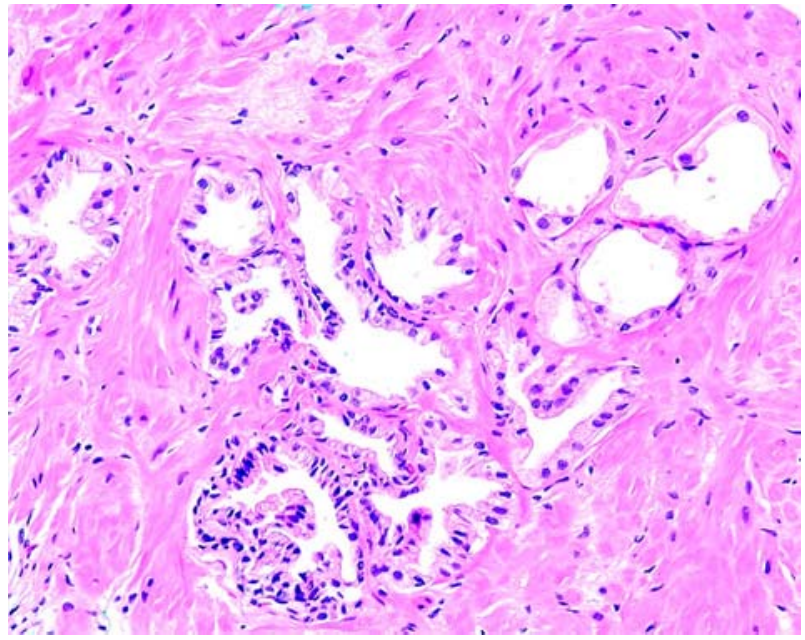

Figure 2-Partial atrophy.

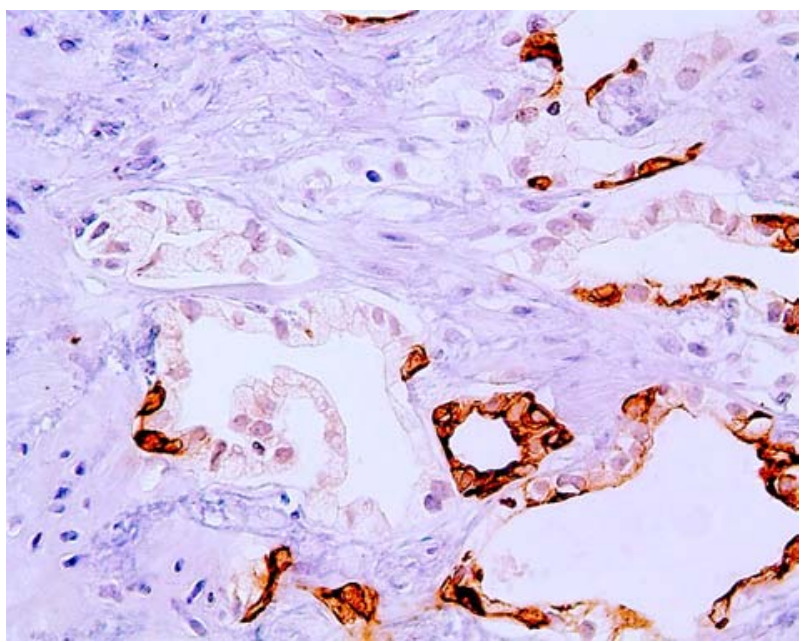

Figure 3 - Partial atrophy (immunohistochemistry: 34âE12).

phy. Inactive or active inflammation is a frequent cause for the lesion (8) and based on a study on autopsies there is evidence that chronic local ischemia may also be a cause of atrophy (5). However, many examples of atrophy are still considered idiopathic in nature. Both inflammation and ischemia are associated with focal forms of atrophy.

The relation of prostatic atrophy to neoplasia is exciting and controversial. This topic was thoroughly commented in our study and discussed in the editorial comments by Dr.H.Samaratunga, Dr. Rodolfo Montironi, and Dr. Liang Cheng (6). 
In diagnostic practice it is not rare to find patients with serum prostate- specific antigen (PSA) elevation and several biopsies showing no atypical, preneoplastic or neoplastic lesions, except prostatic atrophy. Regardless of the cause, we hypothesized that damaged epithelial cells in atrophic acini could be a source of the elevation of PSA. Our study was based on 131 needle prostatic biopsies corresponding to 107 patients. The only diagnosis in all biopsies was focal prostatic atrophy without the presence of cancer, high-grade prostatic intraepithelial neoplasia, or areas suspicious for cancer. A positive and significant association was found between the extent of atrophy and the total or free serum PSA elevation (9). All patients showing $35 \mathrm{~mm}$ or higher linear extent of atrophy in the biopsy cores, had serum PSA above $4 \mathrm{ng} / \mathrm{mL}$. The findings suggest that damaged epithelial cells in atrophic acini, regardless of cause, could be a source of serum PSA elevation.

Prostate-specific antigen is a single chain glycoprotein with proteolytic enzyme activity mainly directed against the major gel-forming protein of the ejaculate (semenogelin). PSA induces liquefaction of semen with release of progressively motile spermatozoa (10). There are several efficient physiologic barriers to prevent the escape of any significant amounts of PSA from the prostatic ductal system: basement membrane of the acini, basal cells lining the acini, prostatic stroma, basement membrane of capillary endothelial cells, and endothelial cells. These barriers normally prevent PSA from entering the general circulation at concentrations of more than $3 \mathrm{ng} /$ $\mathrm{mL}(10)$.

Focal prostatic atrophy represents a form of adaptive response to injury most commonly to inflammation and/or local ischemia. It is intriguing that atrophic acini may produce an excess of serum PSA. Inflammation and/or ischemia are injurious stimuli resulting in diminished oxidative phosphorilation, membrane damage, influx of intracellular calcium, and accumulation of oxygen-derived free radicals (oxidative stress) (11). We speculate that these injurious stimuli may interfere in the physiologic barrier that prevent the escape of any significant amounts of PSA to the general circulation.

Atrophy is a frequent, exciting, intriguing lesion and a relevant subject for further research. $\mathrm{Pa}$ - thologists should include the presence and extent of the lesion in the pathology report.

\section{References}

1. Moore RA: The evolution and involution of the prostate gland. Am J Pathol. 1936;12:599-624.

2. Franks LM: Atrophy and hyperplasia in the prostate proper. J Pathol Bacteriol. 1954;68:617-21.

3. Liavag I: Atrophy and regeneration in the pathogenesis of prostatic carcinoma. Acta Pathol Microbiol Scand [A]. 1968;73:338-50.

4. Cheville JC, Bostwick DG: Postatrophic hyperplasia of the prostate. A histologic mimic of prostatic adenocarcinoma. Am J Surg Pathol. 1995;19:1068-76.

5. Billis A: Prostatic atrophy: An autopsy study of a histologic mimic of adenocarcinoma. Mod Pathol. 1998;11:47-54.

6. Billis A, Leandro LL Freitas, Luis A Magna, Ubirajara Ferreira: Inflammatory atrophy on prostate needle biopsies: Is there topographic relationship to cancer? Int Braz J Urol. 2007;33:355-63.

7. Oppenheimer JR, Wills ML, Epstein JI: Partial atrophy in prostate needle cores: another diagnostic pitfall for the surgical pathologist. Am J Surg Pathol. 1998;22:440-5.

8. Srigley JR: Benign mimickers of prostate cancer. Mod Pathol. 2004;17:328-48.

9. Billis A, Meirelles LR, Magna LA, Baracat J, Prando A, Ferreira U. Extent of prostatic atrophy in needle biopsies and serum PSA levels: is there an association? Urology. 2007;69:927-30.

10. Oesterling JE, Lilja H: Prostate-specific antigen. The value of molecular forms and age-specific reference ranges. In: Vogelzang NJ, Scardino PT, Shipley WU, Coffey DS (eds.), Comprehensive textbook of genitourinary oncology. Baltimore, Williams \& Wilkins. 1996; pp.668-80.

11. Kumar V, Abbas AK, Fausto N: Robbins and Cotran Pathologic Basis of Disease, $7^{\text {th }}$ ed. Philadelphia, Elsevier Sanders.2005; pp.3-46.

Dr. Athanase Billis Full-Professor of Pathology State University of Campinas, Unicamp Campinas, São Paulo, Brazil E-mail: athanase@fcm.unicamp.br 